\title{
El problema de(l) dios. Las bacantes y La Biblia en Teorema
}

\author{
Teorema | Pier Paolo Pasolini | 1968
}

\author{
Amalia Van Aken" \\ IES N¹ "Alicia Moreau de Justo”, Ciudad Autónoma de Buenos Aires
}

Recibido: 5 de junio 2017; aceptado: 30 de noviembre 2017

\begin{abstract}
Resumen
En este trabajo se procuran describir los mecanismos hipertextuales que desarrolla Pasolini en su novela Teorema y en el film homónimo (ambos de 1968), a través de la incorporación del mito de Dionisio relatado en Las Bacantes de Eurípides y de algunos fragmentos de la Biblia. Desde este lugar se analiza la representación de la lucha de clases en Italia a fines de los años sesenta como un escenario más de confrontación entre el poder primitivo, original, digno y cercano a lo natural, representado por la clase obrera y campesina -particularmente por el personaje de Emilia-; y el poder capitalista y burgués, representado por toda la familia. La síntesis que propondrá Pasolini a esta lucha será la destrucción de esta familia a partir de la presencia de un huésped sin nombre y cuyo origen y destino se desconocen; y que por su configuración remite al dios griego Dionisio.
\end{abstract}

Palabras clave: Pasolini | Teorema | Transposición | Bacantes | Biblia | Dionisio

\begin{abstract}
In this paper we attempt to describe the hypertext mechanisms applied by Pasolini in his novel Teorema and the eponymous film (both 1968), through the incorporation of the myth of Dionysus in The Bacchae of Euripides and some passages of the Bible. From this place In considering the foregoing, the representation will be analyzed of the struggle of social classes in Italy in the late sixties as one of the scenarios for two contending powers: one that is primitive, originative, dignified and close to nature, represented by the working class and peasantry -especially by the character of Emilia-; and the capitalist and bourgeois power, represented by the family as a whole. The antithesis proposed by Pasolini to this fight is the destruction of this family from the presence of a nameless guest, whose origin and destination are unknown; and who, by his configuration, refers to the Greek god Dionysius.
\end{abstract}

Key words: Pasolini | Teorema | Transposition | Bacchae | Bible | Dionysus.

\section{Conversión}

Es en el mismo año (1968) cuando Pier Paolo Pasolini escribe la novela Teorema y la lleva al relato audiovisual en el film homónimo. Allí, el dramaturgo, poeta y director italiano se vale de ambos mitos: el Nuevo Testamento y la leyenda dionisíaca recuperada por Eurípides en Las bacantes, para construir su hipótesis: que la lucha entre el viejo y el nuevo poder, proyectada en la reivindicación de la clase obrera y campesina a partir del encuentro con su esencia, cercana a las fuerzas de la naturaleza, es irreconciliable. Esta lucha estará representada a través de la empleada doméstica Emilia (representante de la clase obrera y campesina) y el dueño de la fábrica y pater familiae, Pablo (representante de la pequeño-burguesía, quien le teme a la moral y cuyo nombre nunca se enuncia en el film). El detonante será el personaje del huésped, el que llega para romper la estructura sobre la que se erige el poder. Se trata, entonces, de mostrar la imposibilidad de comunión entre el antiguo y el nuevo orden, entre una sociedad campesina paleo industrial y la nueva sociedad de consumo, entre lo dionisíaco y lo apolíneo; entre lo trágico y lo dramático; entre la naturaleza y la civilización.

Pablo (en la Biblia el mismo apóstol es nombrado como Pablo y como Saulo) ${ }^{1}$ es el ápice de esta familia burguesa; de la sociedad burguesa representada en esta familia. Al igual que el apóstol, se convertirá y descreerá de su identidad previa, aunque no podrá encontrar una nueva. Se desgarrará en su búsqueda, en el grito, aplastado entre el desierto ceniciento y el sol incandescente. Su huida será la oreibasía, la carrera furiosa y salvaje de las 
bacantes, que precederá a su propio sparagmos. ${ }^{2}$ En la Biblia (Hechos; 22-6. Santa Biblia, 1960: p. 1208), cuando "Pablo relata su conversión", leemos lo que puede verse en la escena final del film: "Pero aconteció que yendo yo, al llegar cerca de Damasco, como a mediodía, de repente me rodeó mucha luz del cielo; y caí al suelo.”

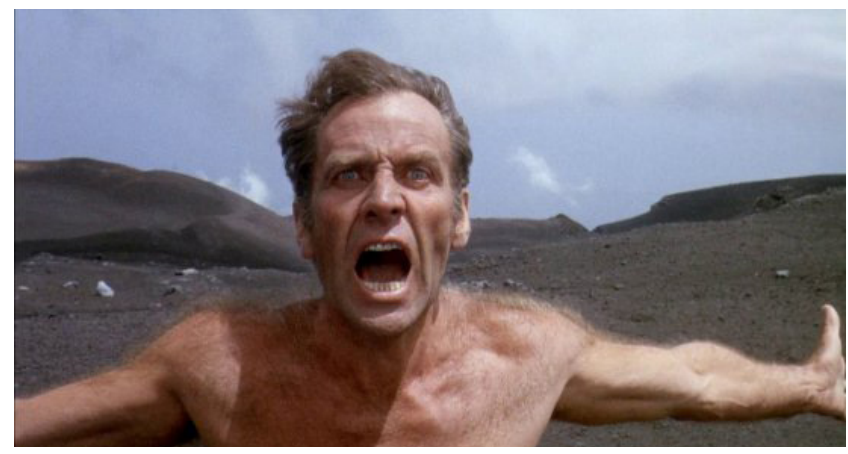

Massimo Girotti como Pablo en el film Teorema (Pier Paolo Pasolini) Italia, 1968.

Pablo entregará la fábrica a los obreros para despojarse de sus pertenencias materiales, pero esto no partirá del deseo de subvertir el orden sino que estará originado en la culpa cristiana. Es el señor feudal que desciende de Dios, quitándole al obrero su posibilidad de rebelarse aceptando un bien cedido en vez de recuperado a partir de la lucha de clases y la revolución obrera. (El periodista -en el film la voz de Pasolini (Teorema, Italia, 1968)- les pregunta a quienes les fue cedida la fábrica: "Pero esta solución religiosa ¿no es la supervivencia de un mundo que ya nada tiene que ver con el nuestro? ¿No nace de la culpa, más que del amor? De modo que un burgués jamás podría recobrar su vida, ni aún perdiéndola...”)

El huésped llevará al límite a estos personajes asentados en el vacío de la materialidad, destruirá la identidad que cada uno de los miembros de la familia creía tener, y, al contrario, elevará a la categoría de "santa" a Emilia, la encarnación de lo primitivo, quien representa al estamento subproletario, como la única clase digna de llevar adelante el verdadero amor por Dios. Y digna del amor que Él le ofrece.

En ambos textos (literario y fílmico) cada analogía entre el huésped y los dioses conforman una gran unidad significante que refiere al quiebre de las estructuras de poder. Dice Mariniello (1999: p. 320): "En el encuentro con el dios los personajes de la historia salen (si bien por poco tiempo) de la prisión de su papel, de su ideología, de su historia; entonces ya no pueden negar su propia 'irrealidad' burguesa."

\section{En busca del azul}

"Pero el día del Señor vendrá como ladrón en la noche, en el cual los cielos pasarán con grande estruendo, y los elementos ardiendo serán deshechos, y la tierra y las obras que en ella hay serán quemadas." (Pedro; 3-10. Santa Biblia, 1960: p. 1318)

Pasolini traza un paralelismo entre ambas teogonías: tanto Cristo como Dioniso/Baco poseen el doble aspecto de lo sagrado: por un lado la serena templanza, la bendición ante la que todos se confiesan; y por otro la violencia, el castigo del soberano Todopoderoso. Ambos dioses mediante la omofagia/teofagia ${ }^{3}$ inducen al creyente a recibir la fuerza del dios (su cuerpo y su sangre) incorporándola a su propio cuerpo.

En Las bacantes el personaje de Penteo, cuyo nombre significa "pena" -cuando se conocen, Baco le profesa: "Bien indica tu nombre la desgracia que te aguarda" (Eurípides; 1951, p. 722)- es arrastrado por su hybris, su arrogancia, cometiendo el error trágico, la hamartía. Su ate ${ }^{4}$ es lo que le impide ver la verdad. En la obra es vencido por un séquito de mujeres poseídas por el delirio dionisíaco, entre las que se encuentra Ágave, su madre, habiéndose él mismo transformado en una de ellas: muere travestido con los hábitos, la mitra y el tirso ${ }^{5}$ de bacante.

Sin embargo quien reconocerá su propio error y pagará por él con el destierro será su madre, cuando se produzca la anagnórisis, el reconocimiento de lo que estaba oculto, y se revele como la asesina de su hijo. Del mismo modo es como Lucía deberá también pagar su soberbia y su ceguera cuando el delirio dionisíaco y la búsqueda infatigable y dolorosa del dios la lleve a entregarse a los muchachos:

“Ágave: -¿Y qué relación hay entre Penteo y mi locura?

Cadmo: -Os imitó no adorando al dios. Sin duda por esto padecisteis igual daño así él como vosotras, y arruinasteis a esta familia y a mí....” (Eurípides; 1951: p. 743)

En Teorema Penteo está representando toda la estructura familiar que tendrá que pagar trágicamente su equivocación (determinada por su condición burguesa).

El personaje de Angelino también está tomado del mensajero en la obra griega. Angelino es quien trae el "verdadero mensaje", el "eu-angelio". En Las bacantes el mensajero es quien anuncia el delirio de las mujeres, su accionar esquizofrénico en el monte Citerón, y luego la muerte de Penteo; también es él quien aconseja la cordura y la veneración a los dioses, y la aceptación de las fuerzas naturales: "Someterse a las leyes divinas y obedecerlas es para mí lo mejor y lo más prudente, y dignos de alabanza los mortales que así lo hacen.” (Eurípides; 1951: p. 738) 
El papel del coro es detonador en esta tragedia; a diferencia de las otras obras de Eurípides, es el coro de bacantes quien hace avanzar la acción. Es omnisciente e incide sobre el actuar de los personajes; crea la atmósfera de la obra, donde se puede encontrar la mirada o el sentimiento tranquilizador de Eurípides y su deseo de paz, que se vale para esto de una leyenda en realidad mucho más cruda y salvaje.

Este mismo deseo de paz también está presente en Teorema. Aquí se puede encontrar la presencia del coro en Emilia, el personaje (la clase) que tiene esta videncia y esta sabiduría, que transmite paz y conoce todo de antemano. La reflexión final del coro señala: "Bajo múltiples formas se muestra el hado, y muchas cosas que no se esperan hacen los dioses, y lo que se aguardaba no viene, y el cielo les da fin inopinado. Así ha sucedido ahora" (Eurípides, 1951: p. 746)

La obra gira en torno a la importancia del respeto al dios, llevada sobre todo por el coro y por el mensajero. El hombre no puede considerarse por encima del poder divino, y su accionar estará siempre determinado por éste. Hay cierto determinismo también en Pasolini: el burgués no puede eludir su condición, y deberá ser destruido ante la fuerza dionisíaca de la igualdad entre los hombres, la anarquía y la insubordinación.

El huésped de Teorema es recibido con una fiesta, tal como era recibido con los sacrificios de bienvenida en las epidemias el dios cosmopolita, benévolo y terrible (Detienne, 1986): Dioniso. Sólo los dioses migratorios tienen derecho a estas fiestas. Dioniso se presenta siempre bajo la máscara del extranjero y se vincula con la fuerza vegetativa, por eso con cada recibimiento se celebra un nuevo nacimiento de la naturaleza. La tragedia misma es la afirmación de una continuidad de lo vital.

Penteo lo describe en Las Bacantes:

Dicen (...) que ha llegado de la Lydia cierto farsante extranjero, cierto encantador de blondos rizos y perfumado cabello, de negros y agraciados ojos, que no las deja ni de día ni de noche, con achaque de celebrar con las doncellas sagradas bacanales. (Eurípides; 1951: p. 714)

Pasolini reivindica la doctrina cristiana "primera" como una vuelta a la búsqueda despojada y original de la colectividad, y de esta manera entrelaza ambos cultos. Nietzsche (2003: p. 27) señala al respecto: "Bajo el encanto de la magia dionisíaca, no sólo se renueva la alianza del hombre con el hombre: la naturaleza enajenada, enemiga o sometida, celebra también su reconciliación con su hijo pródigo, el hombre."

Cuando este dios extraño parte, la familia sale a buscarlo para reencontrarse con él de alguna manera; ya sea siguiendo el mismo camino que ha tomado al partir, ya en la búsqueda del color de sus ojos. Pedro, por ejemplo, invocará el color azul desde "las nuevas técnicas del arte”, ocultando, al mismo tiempo, su insignificante ser. Lucía se entregará a los jóvenes que encuentre por la calle cuyos ojos le recuerden los del huésped. También Pablo quedará prendido de la mirada de un muchacho ojiazul. Inmediatamente después comenzará a desvestirse. Como no pueden comerse a su dios, buscan otras alternativas para asimilarlo, para ser él.

En el texto escrito, estas búsquedas están más evidenciadas por Pasolini, hasta culminar en la búsqueda bíblica de Dios en el desierto. En el film no hay tanta insistencia: el sistema de signos se amplía. La imagen hace mucho más cruda la intención del autor de representar la anulación de los límites del yo, el abandono de las formas que anula el principio de individuación, que es el principio burgués por excelencia; la enfermedad de la que sólo se puede salir mediante la autodestrucción, la locura o la muerte. La familia entera será Penteo descuartizado, asombrado por la luz de una verdad que escapa a su moral y que terminará por sacrificarlo. Mariniello añade: "El dios de Teorema es una especie de detonador de una acción/transformación, es el agente de una conciencia crítica.” (1999: p. 322)

\section{La mirada del otro}

En el paralelismo que establece entre mito y lenguaje cinematográfico parece estar la respuesta al teorema que plantea este texto literario/fílmico: vuelve al mito para dar su mirada sobre el momento político y social en el que está inmerso. A diferencia de Edipo Re (1967), los Apuntti per une Orestiade africane (1970) y Medea (1969), en el film Teorema la puesta en escena es la del "hoy" (la ciudad de Milán de los 60) y no la del universo griego primitivo al que alude. Desarrolla la dimensión política del texto clásico, además de rescatar lo sagrado del mito como naturaleza y su accionar a través del culto y del rito.

El cine es "la lengua escrita de la realidad" (Pasolini, 1970a), donde no hay un salto de registro entre lo que dice el personaje y lo que dice el narrador a través del personaje (o de su mirada del personaje). Es la relación dialéctica entre el sujeto y el mundo de lo real en que ese sujeto actúa. Se trata de que la realidad, opaca y contradictoria, imponga su propio discurso. El lenguaje de la acción del cine se impone por sobre el lenguaje mismo.

Precisamente por esto es que pensamos que Pasolini necesitó poner la novela en andas sobre otro lenguaje, 
trasponerla. Está planteando, a partir del cambio de soporte y del surgimiento de la imagen como nuevo sistema significante, un cambio en las condiciones de producción y de recepción del discurso social. Así su lectura reelaborada desde distintas estrategias enunciativas recreará un nuevo receptor, un receptor que posee ahora un camino más directo para interpretar un sentido.

Bettettini refiere que:

...en el texto literario, cualquier representación (...) deja siempre un amplio margen interpretativo a la integración fantástica del lector, porque se realiza por medio de signos abstractamente simbólicos; en el texto [visual], por el contrario, todo se define en una semiosis mucho más constrictiva y direccional, porque se manifiesta por medio de signos icónicos fuertemente motivados. (...) El problema de la 'traducción' de un texto no puede entonces reducirse a la traslación de [un] universo semántico (...) a otro: no puede reducirse a una equivalencia de enunciados, a una repetición de sentidos organizada detrás de la superficie de significados diferentes. (...) Cuando se 'traduce' (...) se construye, incluso involuntariamente, una nueva estrategia comunicativa, subordinada a circunstancias de consumo completamente diferentes. (1996: pp. 82-83)

También Grüner (2009) intenta responder a esta disyuntiva:

¿Por qué el cine, entonces? ¿Acaso no es -salvo excepciones- la forma estética que corre más peligro de caer en el sueño consolador, de la ilusión conciliatoria de las bellas imágenes? Precisamente por eso: es allí, donde es más difícil hacerlo, que es necesario demostrar el poder que tiene cualquier lenguaje de subvertirse a sí mismo.

Por ejemplo, la desidentificación de estos cuerpos con el ambiente, a veces natural, que los rodea, está trasladada de la novela al film desde el Primerísimo Primer Plano que borra la referencia del mundo exterior. Así muchas veces el rostro queda fuera de contexto en una cámara que se mueve constantemente y no muestra al cuerpo por completo, quedando inscripto en un lugar indeterminado. A diferencia del conformismo erótico burgués, no hay sugestión en este tipo de encuadres. En “Tetis" Pasolini hace una suerte de apología del cuerpo desnudo y del sexo. El cuerpo constituye el símbolo de una realidad corpórea, protagonista de una cultura del pasado popular y "primitivo"; es la realidad que todavía pertenece del todo al hombre. Por el contrario, "los burgueses, creadores de un nuevo tipo de civilización” ( $\mathrm{Pa}$ solini, 1983, p. 99) sólo pueden lograr desrealizar el cuerpo. En Teorema no hace falta que se abra el plano para ver el cuerpo desnudo ni las escenas eróticas; porque no espera que el espectador se identifique con ellas, sólo que sepa lo que ocurrió: que el huésped se acerca a cada uno de los personajes a través de una relación de amor.
Además, a diferencia de la mayoría de sus films, los actores que Pasolini elige en éste son estereotipadamente bellos. Una manera, tal vez, de reforzar la imagen que la sociedad burguesa tiene de sí misma.

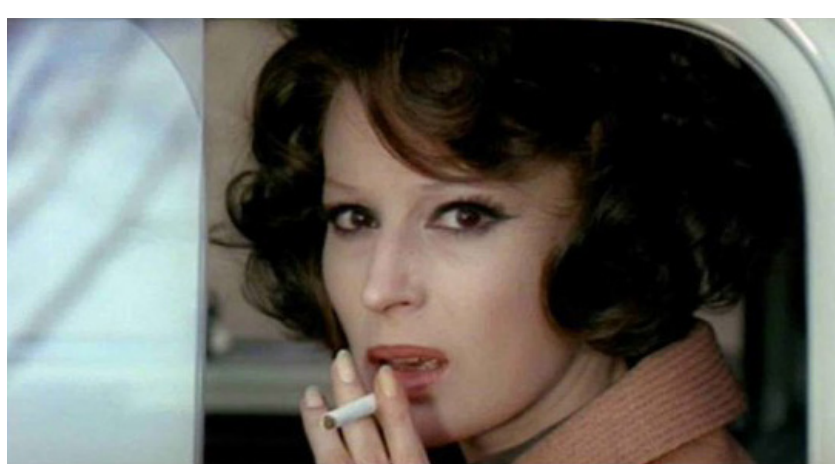

Silvana Mangano como Lucía en el film Teorema (Pier Paolo Pasolini) Italia, 1968.

\section{La moral burguesa}

Cuando el huésped ha decidido partir, a manera de "confesión" los integrantes de esta familia (sostenida por los pilares de la sociedad ática: cordura, racionalidad, represión colectiva) le expresan lo que su presencia y su ida les provoca. Él no dice nada. Este momento en la novela es una poesía en primera persona de cada personaje en la que se vislumbra el destino final de cada uno:

Pedro: "Es pues, a través de la destrucción de todo lo / que me igualaba a los demás como me convierto / (...) en un DIFERENTE.” (Pasolini; 1970b: p. 109)

Odetta: “...debía protegerme (...) / para ocultar los penosos síntomas de mi enfermedad de clase (...) / aquella enfermedad amenazaba de continuo / en mí, con salir a la luz / con desenmascararme y desenmascararlo todo." (Pasolini; 1970b: p. 111)

Lucía: “¿Quieres decirme, acaso, joven como eres, que es posible / el reemplazo de tu cuerpo y de tu alma / por el cuerpo y el alma de un muchacho que se te parezca? / ¿Qué sus ojos tengan para mí la luz azulada del deseo mezclado con la ternura?” (Pasolini; 1970b: p. 116)

Pablo: "Has venido, pues, a esta casa para destruir (...). / has destru'ido, simplemente, (...) la idea que he tenido siempre de mí mismo.” (Pasolini; 1970b: p. 117)

Lo que el huésped genera en Pablo es la pulsión de no poseer; un sentimiento que no ha experimentado nunca. Se produce, así, una igualación entre todos los miembros de la familia burguesa. Por primera vez hay algo, fuera de su estructura materialista, que los unifica: el amor y la pertenencia al huésped. 
Emilia, cuando se va este dios del deseo y del cambio, es la única que no le habla de lo que su presencia provocó en ella. Y es la única que recibe su palabra en el poema que se titula "Complicidad entre el subproletariado y dios" donde él le dice (a modo profético):

Serás la única en saber, cuando haya partido, / que no volveré nunca, y me buscarás donde debas buscarme: no mirarás siquiera / la calle por la cual me alejaré y desapareceré, / la calle que, en cambio, todos los demás mirarán... (Pasolini; 1970b: p. 119)

Emilia representa el lugar de la empleada doméstica, la posición social de la campesina. La nueva empleada se llama también Emilia, y también proviene del mundo campesino. Ella es la única que ha sido tocada por el dios que puede convertirse en santa, purificarse, hacer milagros, elevarse, convertirse en manantial enterrándose en el lugar de una futura construcción gigante, porque proviene del mundo puro, que no está afectado por la putrefacción de la burguesía: “...la angustia es una situación típicamente burguesa... El subproletariado tiene otro tipo de angustia, una angustia prehistórica respecto a la angustia existencialista burguesa, históricamente determinada." (Pasolini, 1965)

Dice el periodista en la novela, cuando Emilia está levitando:

¿El moralismo es la religión (cuando existe) de la burguesía? (...)

¿De modo que la religión sobrevive hoy, como hecho auténtico, únicamente en el mundo campesino, es decir, en el tercer mundo?

¿No es esto lo que quiere decir esta santa loca, a las puertas de Milán, ante las primeras fábricas?

¿No es ella una terrible acusación viviente contra la burguesía que ha reducido (en el mejor de los casos) la religión a un código de conducta?

¿De modo que mientras esta santa campesina puede salvarse, siquiera en este agujero histórico, ningún burgués podrá salvarse, ni como individuo ni como colectividad? (Pasolini; 1970: pp. 195-196).

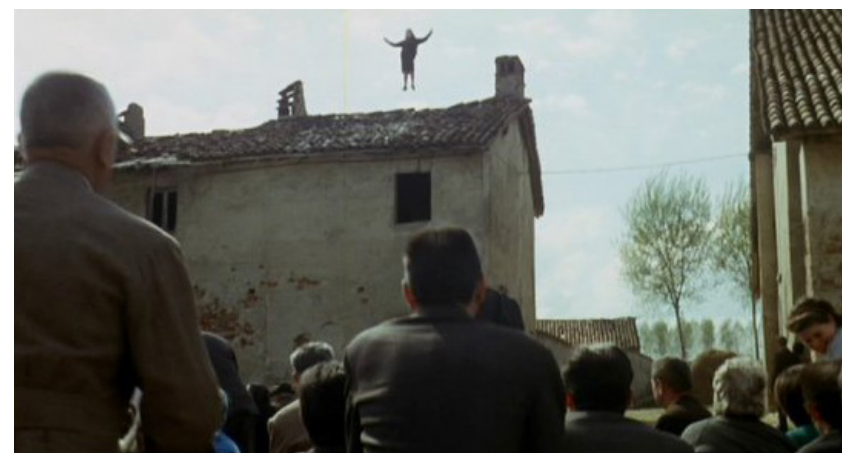

Laura Betti como Emilia en el film Teorema (Pier Paolo Pasolini) Italia, 1968.
La familia burguesa, en cambio, tendrá que destruirse por completo, resquebrajarse y desunirse, para hacer evidente su antinaturalidad y su desunión congénita; pero es poco probable que después pueda renacer de sus cenizas. Tal vez alguno de sus integrantes lo intente, sobre todo los hombres: Pedro y Pablo (los que predican el evangelio de Dios en el Nuevo Testamento). El primero dando cuenta de la destrucción absoluta llevada al arte tal vez pueda rescatar algo de su ser:

Ninguno debe comprender que el autor no vale nada, que es un ser anormal, inferior, que es como un gusano que se retuerce para sobrevivir (...). Todo debe presentarse como perfecto; basado en reglas desconocidas y, por lo tanto, imposibles de juzgar. (Pasolini; 1970: p. 161).

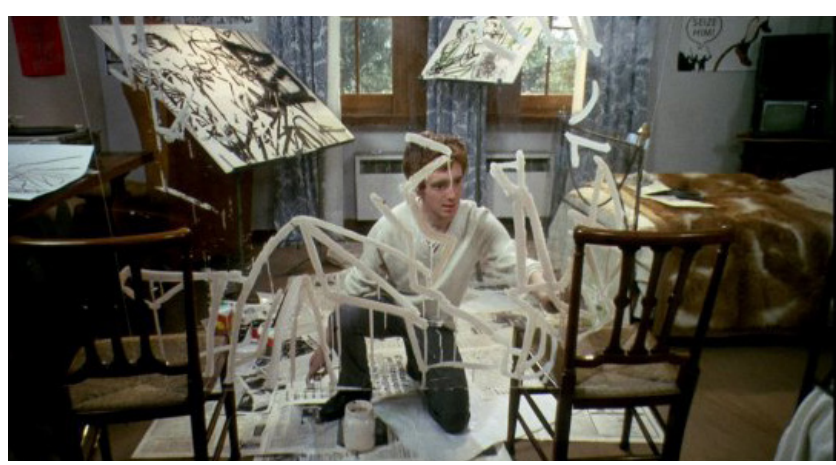

Andrés José Cruz Soublette como Pedro en el film Teorema (Pier Paolo Pasolini) Italia, 1968.

Pablo, en cambio, lo hará abandonando por completo la vida urbana y burguesa. Desnudo por el desierto será como el apóstol de su nombre y buscará predicar un evangelio que no entiende cómo se le ha internado en el cuerpo.

Odetta no podrá producir algo con su posesión dionisíaca. Demasiado débil, o demasiado valiente, se abandonará al autismo en una clínica de su clase, y por siempre mantendrá encerrado en su puño lo que sólo se le dio a conocer una vez: el poder del sexo de Dios, que descubrió su propio sexo y que le fue atribuido por la mirada del padre, quien permitió (a partir de su propio amor por el huésped) que ella pudiera cambiar su objeto de deseo. Efectivamente, cuando Odetta da pasos en el jardín y los mide con un metro, está calculando las distancias que había entre ella, su padre y el huésped la última vez que estuvieron sentados allí, cuando el padre le cedió a ella su propio derecho al amor por esta irracionalidad, por este caos representado en el huésped:

¿Qué debería valer más: tu identificación o tu ser? Tú no sabes elegir, tierna Odetta, porque estás / ciega: / Así has elegido. Así has vivido. Y te debates / inútil, Perdida entre un recuerdo demasiado / hermoso / 
Y una realidad que te lleva del sueño a la locura. (Pasolini; 1970: p. 89)

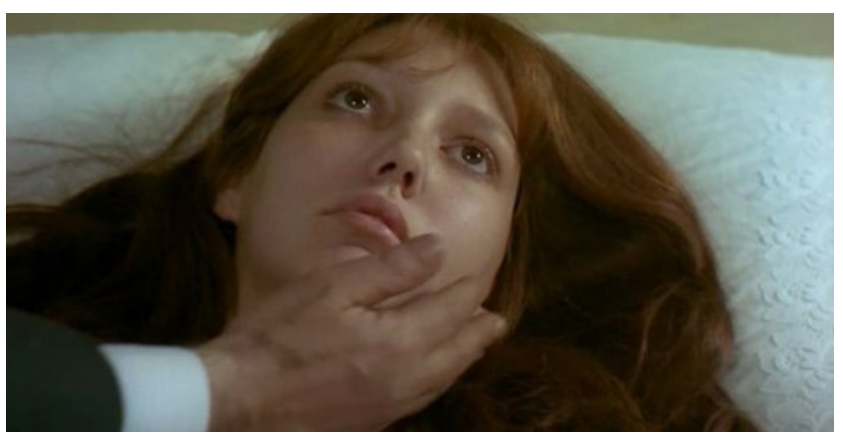

Anne Wiazemsky como Odetta en el film Teorema (Pier Paolo Pasolini) Italia, 1968.

Teorema es, entonces, la alegoría de una lucha irresoluble donde no hay antítesis, donde coexiste lo doble: lo sagrado y lo desconsagrado. El film tiene una estructura casi matemática, simétrica, circular; como un efecto análogo a la atemporalidad que propone la novela; y, a su vez, a la temporalidad circular del mito, que se actualiza cada vez que se repite su ritual cultual. Termina donde comienza: en el desierto, lugar de nacimiento y de muerte, donde lo liberado es llevado al extremo, el lugar de la búsqueda del cuerpo desacralizado y solo de Pablo, el "sin nombre", quien deberá finalmente soportar toda la luz del sol sobre su cuerpo desnudo.

La forma en que se estructura el pensamiento en el seno de cada clase impide, en el caso pequeñoburgués, acercarse a lo espiritual, a lo que tiene que ver con la entrega de los cuerpos (y con ellos la del alma). Por eso en la novela Pasolini pone el énfasis en la expresión de "actuar antes de comprender". Pedro, Lucía, Odetta, Pablo tienen que actuar antes de comprender. Dejar a un lado el pensamiento que limita al comportamiento, y dejarse ser. Eso es lo que logra esta santa campesina que ni siquiera tiene que confesarse ante su dios, porque lo ha asimilado de una manera más profunda, sin necesitar buscarlo superficialmente como los demás. Emilia "no quiere comprender" que tiene que comer, por ejemplo. Ella actúa, y en vez de azul se vuelve verde. Todos, menos ella, acaban por perder o traicionar a Dios.

El poema "Los primeros a quienes amamos" está dedicado al huésped, probablemente. El narrador lo incita a adentrarse en ese universo putrefacto y despedazarlo:

Disfruto de tus primeras ingenuas y obstinadas experiencias,

Tímido dinamitero, amo de las noches libres,

Pero recuerda que tú estás aquí sólo para ser odiado,

Para derribar y matar. (Pasolini; 1970: p. 60)

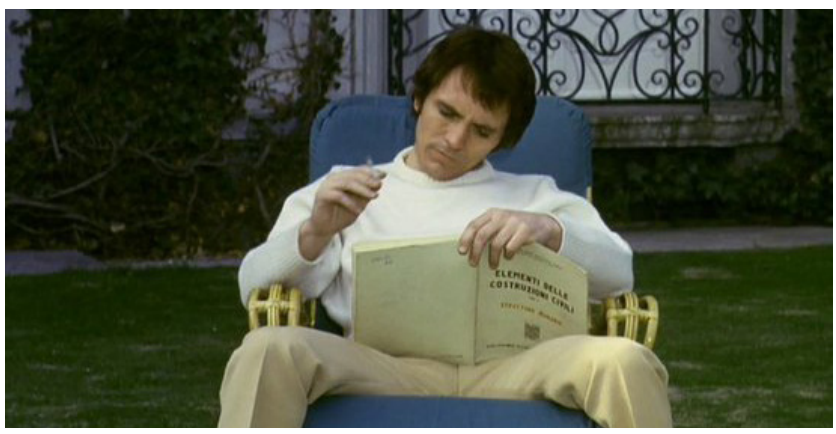

Terence Stamp como “el huésped” en el film Teorema (Pier Paolo Pasolini) Italia, 1968.

Pasolini trata, al fin y al cabo, en esta obra, de desnaturalizar los preceptos del régimen neocapitalista que, en su desigualdad de condiciones para con los hombres, sacrifica la existencia de unos para el vital desarrollo de quienes detentan el poder.

\section{Referencias}

Agamben, G. (2006). El tiempo que resta. Un comentario a la Carta de los romanos. Madrid: Trotta

Bettettini, G., (1996). Cap. 3: Las transformaciones del sujeto en la traducción, en La conversación audiovisual. Madrid: Ed. Cátedra, $2^{\circ}$ ed.

Detienne, M. (1986). Dioniso a cielo abierto, Barcelona: Ed. Gedisa.

Eurípides. (1951). Las bacantes en Obras dramáticas. Buenos Aires: Ed. El Ateneo.

Festugière, A. (1986). La esencia de la tragedia griega, París: Les belles lettres.

Grüner, E. (2009). “Los soles de Pasolini” Revista La Fuga No 10. ISSN: 0718-5316. Recuperado de: http://www.lafuga.cl/los-solesde-p.... Última consulta: 01/09/16

Mariniello, S. (1999). Pier Paolo Pasolini, Madrid: Ed. Cátedra.

Nápoli, J.T. (2004) “Mito y rito dionisíaco en Bacantes de Eurípides: sobre el origen ritual del teatro". Ponencia presentada en las Jornadas Diálogos entre Literatura, Estética y Teología, Facultad de Filosofía y Letras, Universidad Católica Argentina. Buenos Aires. Recuperado de: http://bibliotecadigital.uca.edu.ar... 
Nietzsche, F. (2003). El origen de la tragedia. Buenos Aires: Ed. Libertador (Andrómeda ed.).

Pasolini, P.P. (1983) “Tetis” en AA.VV, Erotismo y destrucción, Madrid: Ed. Fundamentos

Pasolini, P.P.; Rohmer, E. (1970a). Cine de poesía contra cine de prosa. Barcelona: Ed. Anagrama. Pp. 5-41.

Pasolini, P.P. (1970b). Teorema, Buenos Aires: Ed. Sudamericana.

Pasolini, P.P. (1965). “Autopresentación” en Revista Nuestro Cine, No 46, Madrid. pp 13 -19. Traducción y montaje de textos: Ricardo Diaz-Delgado. Recuperado de: http://www.adversus.org/indice/nro4... Última consulta: 01/09/16

Santa Biblia (2009). Estados Unidos: La Iglesia de Jesucristo de los Santos de los Últimos Días. Recuperado de: http://media.ldscdn. org/pdf/lds-scr... Última consulta: 01/09/16

1 Según Agamben, Pablo es el sobrenombre que Dios, o Pablo mismo, se da como un signo del cambio de su persona cuando acepta su llamada o vocación mesiánica por parte divina: la mal denominada “conversión” en el camino de Damasco. (Agamben, 2006: 20).

2 Sparagmos: Literalmente significa piezas desmembradas, desmenuzadas, violadas o fragmentadas. En sus acepciones de despedazamiento de cuerpos y conducta convulsiva y espasmódica, el término puede indicar desmembramiento tanto moral y sociopolítico como físico y formal-literario.

3 Omofagia: ingestión de carne cruda; ritual que provenía luego del descuartizamiento o sparagmos. Teofagia: ingestión de un alimento que simbólicamente alude a un dios (por ejemplo la ostia simboliza el cuerpo de Cristo; por lo tanto comerla implica ingerir el cuerpo de Dios).

$4 \quad$ Ate: furia. Insensatez producida por la furia, y también el daño producido, la culpa, el castigo por lo realizado ciegamente.

5 Tirso y mitra: atributos que portaban las bacantes en sus rituales. El tirso era una vara, bastón o cetro envuelto en hiedra u hojas de parra, que representaba la fertilidad; la mitra era una cinta que se colocaban las bacantes en el pelo (al parecer calmaba el dolor de cabeza producido por la bebida, por eso el dios Dioniso la portaba bajo la corona de hiedra). 